九州大学学術情報リポジトリ

Kyushu University Institutional Repository

\title{
In situ production of bulk intermetallic-based nanocomposites and nanostructured intermetallics by high-pressure torsion
}

\section{Edalati, Kaveh}

Department of Materials Science and Engineering, Faculty of Engineering, Kyushu University I WPI, International Institute for Carbon-Neutral Energy Research (I2CNER), Kyushu University

Toh, Shoichi

Research Laboratory for High Voltage Electron Microscopy, Kyushu University

Watanabe, Masashi

Department of Materials Science and Engineering, Lehigh University

Horita, Zenj i

Department of Materials Science and Engineering, Faculty of Engineering, Kyushu University | WPI, International Institute for Carbon-Neutral Energy Research (I2CNER), Kyushu University

http://hdl. handle. net/2324/26374

出版情報：Scripta Materialia. 66 (6)，pp.386-389，2012-03. Elsevier バージョン：

権利関係 : (C) 2011 Acta Materialia Inc. 


\title{
In situ production of bulk intermetallic-based nanocomposites and nanostructured intermetallics by high-pressure torsion
}

\author{
Kaveh Edalati, ${ }^{a, b}, *$ Shoichi Toh, ${ }^{c}$ Masashi Watanabe ${ }^{d}$ and Zenji Horita $^{a, b}$ \\ ${ }^{a}$ Department of Materials Science and Engineering, Faculty of Engineering, Kyushu University, \\ Fukuoka 819-0395, Japan \\ ${ }^{b}$ WPI, International Institute for Carbon-Neutral Energy Research (I2CNER), Kyushu University, \\ Fukuoka 819-0395, Japan \\ ${ }^{\mathrm{c}}$ Research Laboratory for High Voltage Electron Microscopy, Kyushu University, Fukuoka \\ 819-0395, Japan \\ ${ }^{\mathrm{d}}$ Department of Materials Science and Engineering, Lehigh University, Bethlehem, PA 18015, USA
}

\begin{abstract}
Micropowder mixtures of $\mathrm{Al}-50 \mathrm{~mol}$ \% Ni were severely deformed by high-pressure torsion and $\mathrm{Al}_{3} \mathrm{Ni}_{2} / \mathrm{Ni}$ nanocomposites were produced. The hardness increased with straining, as a consequence of nanograin formation and high-strain-induced solid-state reactions, and saturated to a steady-state level, $920 \mathrm{Hv}$. The reactions were completed and nanostructured AlNi intermetallics were produced by subsequent annealing. The formation of nanostructured intermetallics was feasible in this process at significantly low temperatures because of the rapid diffusion and short diffusion paths resulting from intense shearing.
\end{abstract}

Keywords: Ultrafine-grained microstructure; Severe plastic deformation (SPD); High-pressure torsion (HPT); Mechanical alloying.

* Corresponding author at: Department of Materials Science and Engineering, Faculty of Engineering, Kyushu University, Fukuoka 819-0395, Japan. Tel./fax: +81 92802 2992; e-mail: kaveh.edalati@zaiko6.zaiko.kyushu-u.ac.jp. 
Intermetallic materials, which have characteristics of both metals and ceramics, exhibit unique physical, chemical and mechanical properties especially in nanostructured form. Numerous routes for the production of intermetallics from their elemental constituents have been developed, including casting, thermomechanical processing, reactive sintering, mechanical alloying, physical vapor deposition and electrodeposition [1]. Despite this plethora of methods for production of intermetallics [1] and intermetallic-based composites [2], fabrication of bulk nanostructured intermetallics and their nanocomposites is still a challenging task.

Nanostructured intermetallics and their nanocomposites are generally produced by two-step processes: the first step involves synthesis of nanopowder intermetallics from their elemental constituents by methods such as chemical synthesis [3], high-energy ball milling [4], inert gas condensation [5] and laser vaporization condensation [6]; and the second step is the consolidation of nanopowders into bulk forms [1,2]. However, high temperatures need to be used in the second step to achieve a full consolidation and retaining nanograins is difficult when processing at high temperatures.

It has been documented that application of high-temperature compression to elemental nanopowders can be used for the in situ production of bulk nanostructured intermetallics [7], but the starting materials need to be in the form of nanopowders, which are in general not easily fabricated. Application of severe plastic deformation (SPD) methods [8,9] to coarse-grained intermetallics is another approach for production of bulk nanostructured intermetallics [10,11]. However, the starting bulk intermetallics need to be produced by casting at extremely high temperatures and this is a challenging task. The SPD process is also applicable for cold consolidation of metal-based nanocomposites with large fractions of intermetallics or ceramics [12,13], but the starting intermetallics or ceramics should be in the form of nanopowders.

In this study, and for the first time, bulk intermetallic-based nanocomposites and nanostructured intermetallics in the Al-Ni system are generated from elemental micropowder mixtures by high-pressure torsion (HPT). Among different SPD methods, HPT, in which a disc is subjected to high pressure and simultaneous torsional straining, was selected for this study because it has several advantages: (i) HPT has ability to impose extremely large shear strains, $\gamma$ ( $\gamma=2 \pi r N / h$, where $r$ is the distance from disc center, $N$ is the number of revolutions and $h$ is the disc thickness) [14]; (ii) HPT provides a unique opportunity for consolidation of different kinds of materials even including hard and less ductile intermetallics and ceramics [15]; and (iii) HPT can be used for controlling phase changes in metals [16,17] and ceramics [18].

$\mathrm{Al}$ (99.99\%) powders with $<75 \mu \mathrm{m}$ particle sizes were mixed with 50 mol.\% Ni (99.99\%) powders with $<150 \mu \mathrm{m}$ particle sizes. As reference materials, discs of pure $\mathrm{Al}$ (99.99\%) and pure $\mathrm{Ni}$ (99.99\%) $10 \mathrm{~mm}$ in diameter and $0.8 \mathrm{~mm}$ thick were also used. HPT was conducted at $573 \mathrm{~K}$ to consolidate the powder mixtures to discs $10 \mathrm{~mm}$ in diameter and $0.8 \mathrm{~mm}$ thick under a pressure of 6 GPa. Shear strain was introduced through rotations for either $N=3,10,50$ or 120 revolutions with a rotation speed of $\omega=1.0 \mathrm{rpm}$. The sample processed for $N=50$ was subsequently annealed at 673 $\mathrm{K}$ for $24 \mathrm{~h}$.

The HPT-processed discs were first polished to a mirror-like surface and Vickers 
microhardness was measured with an applied load of $200 \mathrm{~g}$ for $15 \mathrm{~s}$ along the radii at eight different radial directions. X-ray diffraction (XRD) analysis was performed using $\mathrm{Cu} \mathrm{K} \alpha$ radiation. Scanning electron microscopy (SEM) at $20 \mathrm{kV}$ was used for microstructural observations. The sample density was determined by Archimedes’ principle. Finally, $3 \mathrm{~mm}$ discs were cut at $3.5 \mathrm{~mm}$ from the disc center and thinned with an electrochemical polisher $\left(10 \% \mathrm{HSO}_{4}, 10 \% \mathrm{HNO}_{3}, 80 \% \mathrm{CH}_{3} \mathrm{OH}\right)$ and examined by transmission electron microscopy (TEM) at $300 \mathrm{kV}$.

$\mathrm{XRD}$ analysis, as shown in Figure 1, confirms that the $\mathrm{Al}_{3} \mathrm{Ni}$ intermetallic is formed at the early stages of straining ( $\gamma=80$ ) but transforms to an $\mathrm{Al}_{3} \mathrm{Ni}_{2}$ intermetallic on further straining and to an AlNi intermetallic by subsequent annealing at $673 \mathrm{~K}$ for $24 \mathrm{~h}$. The material at large strains $(\gamma>$ 270) consists of $\sim 50$ mol.\% (84 vol.\%) $\mathrm{Al}_{3} \mathrm{Ni}_{2}$ and $\sim 50$ mol.\% Ni after HPT and of $100 \%$ AlNi after annealing.
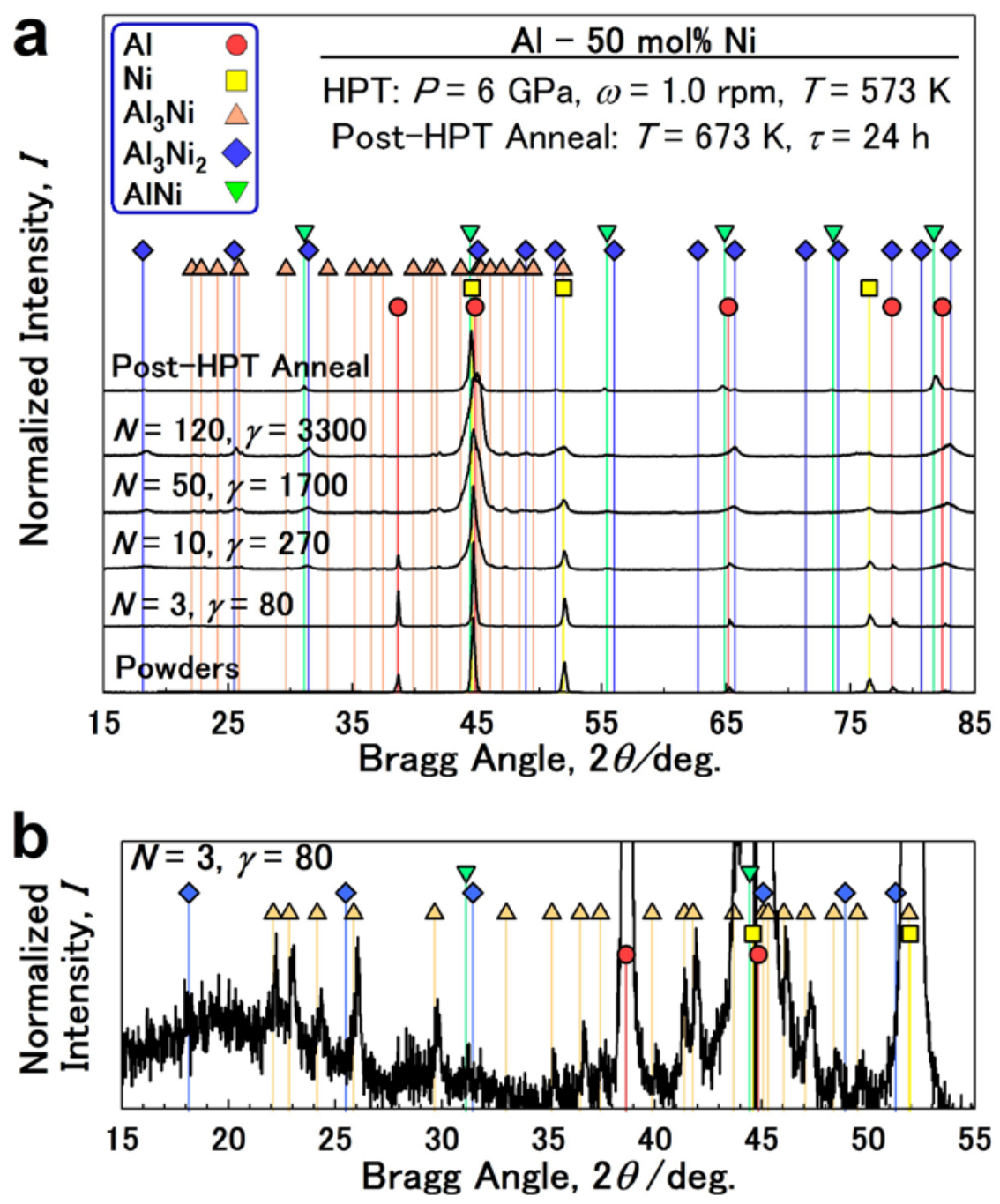

Figure 1. XRD profiles for (a) samples processed by HPT at $573 \mathrm{~K}$ for $N=3,10,50$ and 120 turns and sample post-HPT annealed at $673 \mathrm{~K}$ for $24 \mathrm{~h}$ including as-received $\mathrm{Al} / \mathrm{Ni}$ micro-powder mixtures, and (b) sample processed for $N=3$ in enlarged scale to check $\mathrm{Al}_{3} \mathrm{Ni}$ formation.

The SEM results are shown in Figure 2a. It is apparent that $\mathrm{Al}$ and Ni phases are distinctive after compression, but the two phases are elongated significantly in the shear direction and their 
thickness is reduced with straining. At large stains (e.g. $\gamma=1400$ ), shear bands disappear and Al and $\mathrm{Ni}$ entirely mix and the microstructure becomes uniform at the micrometer level.

TEM bright-field images, dark-field images, corresponding selected-area electron diffraction (SAED) patterns, high-resolution images and corresponding diffractograms obtained by fast Fourier transform (FFT) analyses are shown in Figure $2 \mathrm{~b}$ and c for a sample after HPT for $\gamma=1400$, and in Figure $2 \mathrm{~d}$ and e for a sample after post-HPT annealing at $673 \mathrm{~K}$ for $24 \mathrm{~h}$. TEM characterization indicates that the microstructures consist of nanograined $\mathrm{Al}_{3} \mathrm{Ni}_{2}$ intermetallics separated by boundaries with high angles of misorientations between the grains of different phases after HPT and of nanograined AlNi after subsequent annealing; these findings are consistent with the XRD analysis. The average grain size is $\sim 28 \mathrm{~nm}$ after HPT but increases to $\sim 50 \mathrm{~nm}$ following the annealing. Detailed analysis of the lattice fringes in high-resolution images and their corresponding diffractograms in Figure 2c and e also clearly confirms the presence of nanograined $\mathrm{Al}_{3} \mathrm{Ni}_{2}$ intermetallics after HPT and of nanograined AlNi after annealing, respectively.

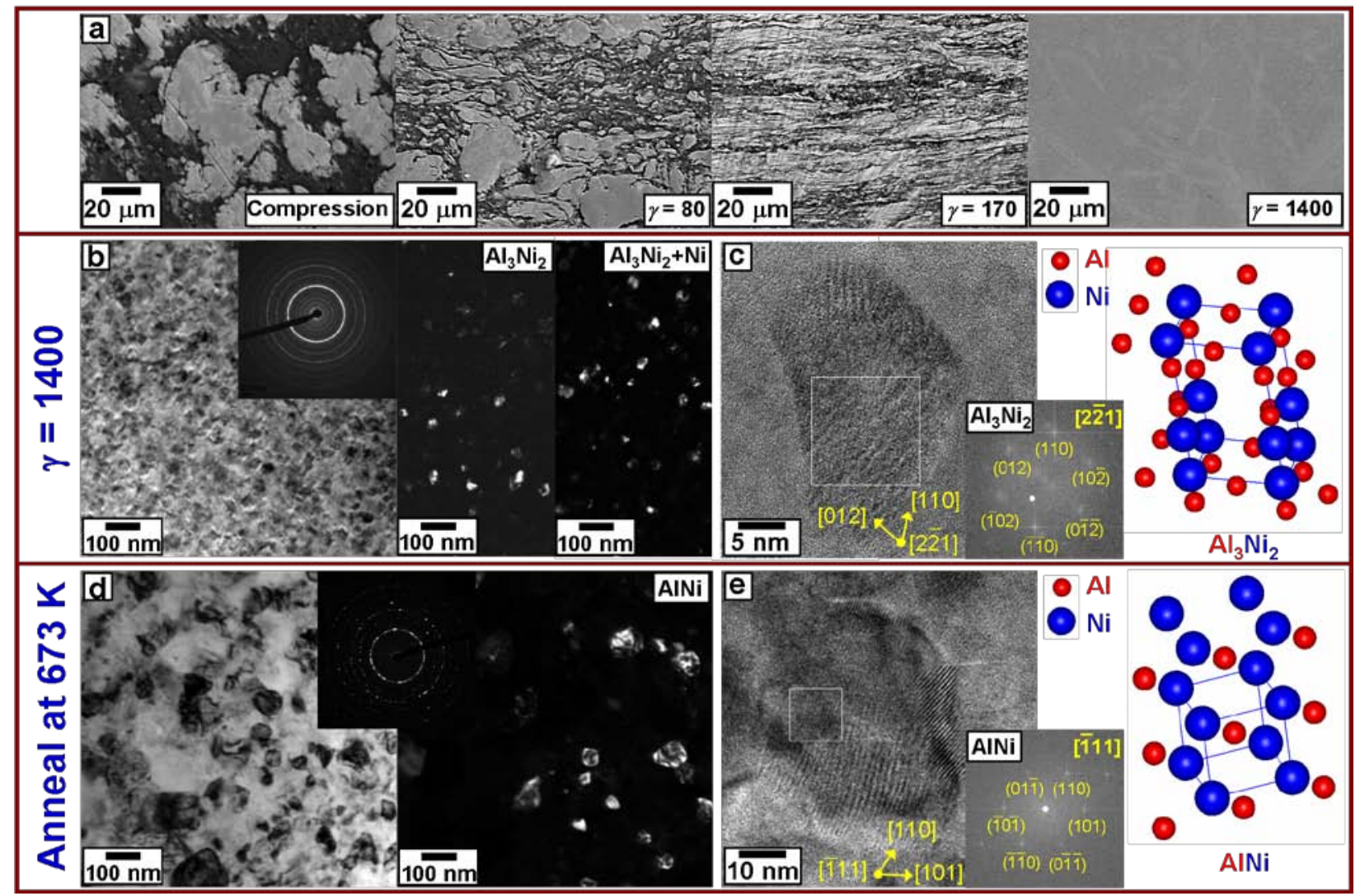

Figure 2. Microstructures of samples. (a) SEM micrographs after compression and after HPT for strains of $\gamma=80,170$ and 1400. (b) TEM bright-field image, SAED pattern and dark-field images corresponding to $\mathrm{Al}_{3} \mathrm{Ni}_{2}$ and $\mathrm{Ni}+\mathrm{Al}_{3} \mathrm{Ni}_{2}$ phases for sample processed for $\gamma=1400$. (c) High-resolution image and corresponding FFT analysis from square region for $\mathrm{Al}_{3} \mathrm{Ni}_{2}$. (d) TEM bright-field image, SAED pattern and dark-field images corresponding to AlNi phase for sample subjected to post-HPT annealing at $673 \mathrm{~K}$ for $24 \mathrm{~h}$. (e) High-resolution image and corresponding FFT analysis from square region for AlNi. 
Figure 3 plots the hardness variation with the shear strain for $\mathrm{Al} / \mathrm{Ni}$ powder mixtures processed for $N=3-120$ turns including the sample subjected to subsequent annealing at $673 \mathrm{~K}$ for $24 \mathrm{~h}$. The levels of hardness for as-cast AlNi and the saturation levels of hardness for as-HPT pure $\mathrm{Al}$ and $\mathrm{Ni}$ after processing at $298 \mathrm{~K}$ are also included. The hardness is less than $100 \mathrm{Hv}$ until the significant increase occurs at $\gamma=100-200$ and, with a further increase in the strain, the hardness saturates to a steady-state level as high as $920 \mathrm{Hv}$. It should be noted that the reactions end and no changes in the grain size occur at c $>200$, and this is why a steady-state of hardness appears at c $>200$. Figure 3 shows that the hardness level is reduced by annealing, but nevertheless still remains as high as 800 Hv. This hardness value is consistent with the levels reported for nanostructured AlNi [5] but is much higher than the levels for as-HPT pure $\mathrm{Al}$ and $\mathrm{Ni}$ as well as higher than the level for as-cast AlNi.

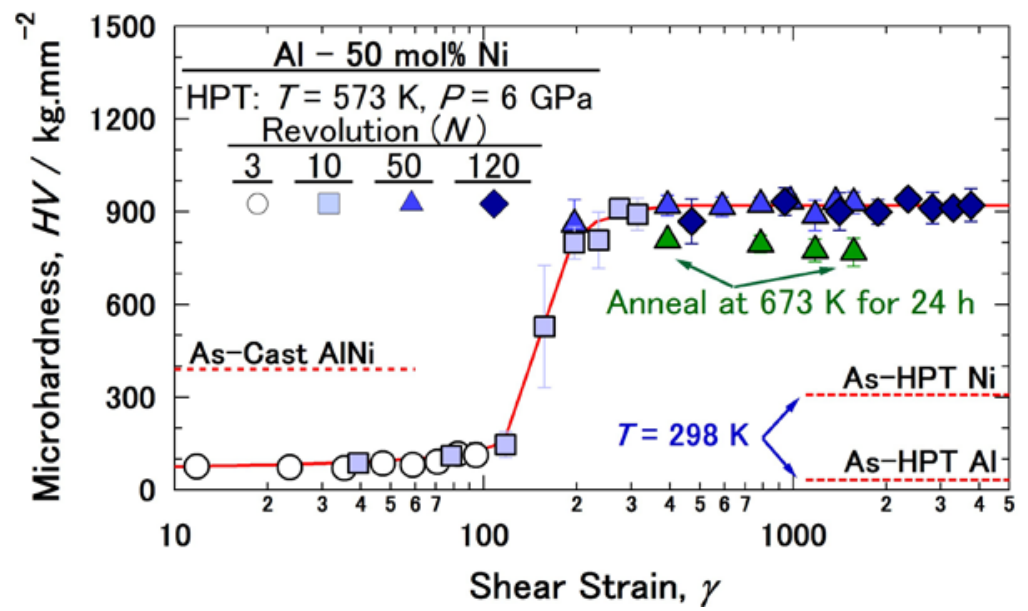

Figure 3. Vickers microhardness plotted against shear strain for samples processed by HPT at $573 \mathrm{~K}$ for $N=3,10,50$ and 120 and sample post-HPT annealed at $673 \mathrm{~K}$ for $24 \mathrm{~h}$ including hardness levels for as-HPT pure $\mathrm{Al}$ and $\mathrm{Ni}$ and as-cast AlNi.

Density measurement reveals that a relative density of $\sim 100 \%$ is achieved just after $N=3$ turns. The relative density, however, decreases at very large strains $(\gamma>1700)$ because of formation of micropores throughout the sample. It should be noted that the formation of micropores was confirmed by optical microscopy and SEM, but pores having sizes at the submicrometer or nanometer levels could not be detected using TEM.

Several questions arise from the current investigation. Why is a non-equilibrium $\mathrm{Al}_{3} \mathrm{Ni}_{2} / \mathrm{Ni}$ mixture formed after HPT? Why is equilibrium AlNi intermetallic formed after annealing? Why is the grain size reduced to the nanometer level in $\mathrm{Al} / \mathrm{Ni}$ mixtures whereas it is $1400 \mathrm{~nm}$ for pure $\mathrm{Al}$ [19,20] and $170 \mathrm{~nm}$ for pure $\mathrm{Ni}$ [21]? Why is a steady state reached at large shear strains? The reasons are outlined below and schematically illustrated in Figure 4.

The solid-state reactions and formation of new phases are controlled by atomic diffusion in this study. Obviously, the paths for volume diffusion are significantly shortened after imparting intense shear strain, e.g. a particle with an average diameter of $\sim 10 \mu \mathrm{m}$ is significantly elongated, which results in formation of extremely thin grains with a thickness of $\sim 100 \mathrm{~nm}$ after processing for $\gamma=$ 100. Furthermore, the diffusivity can be strongly enhanced because of the presence of a high 
density of lattice defects and large fractions of high-angle grain boundaries formed during HPT [22-24]. Since the diffusion of $\mathrm{Ni}$ in $\mathrm{Al}$ is faster than the diffusion of $\mathrm{Al}$ in $\mathrm{Ni}$, the $\mathrm{Ni}$ atoms diffuse to the $\mathrm{Al}$ matrix and form $\mathrm{Al}$-rich $\mathrm{Al}_{3} \mathrm{Ni}$ intermetallics, which then transform to the $\mathrm{Al}_{3} \mathrm{Ni}_{2}$ intermetallics with further diffusion of $\mathrm{Ni}$ atoms (Fig. 4c). The reaction is terminated after the formation of $\mathrm{Al}_{3} \mathrm{Ni}_{2}$ (Fig. 4d) because the diffusivity of $\mathrm{Ni}$ is very slow in the intermetallic [25]. The Ni diffusion in the intermetallic, however, is enhanced during annealing at $673 \mathrm{~K}$, and becomes sufficient for the formation of equilibrium AlNi intermetallics (Fig. 4e).

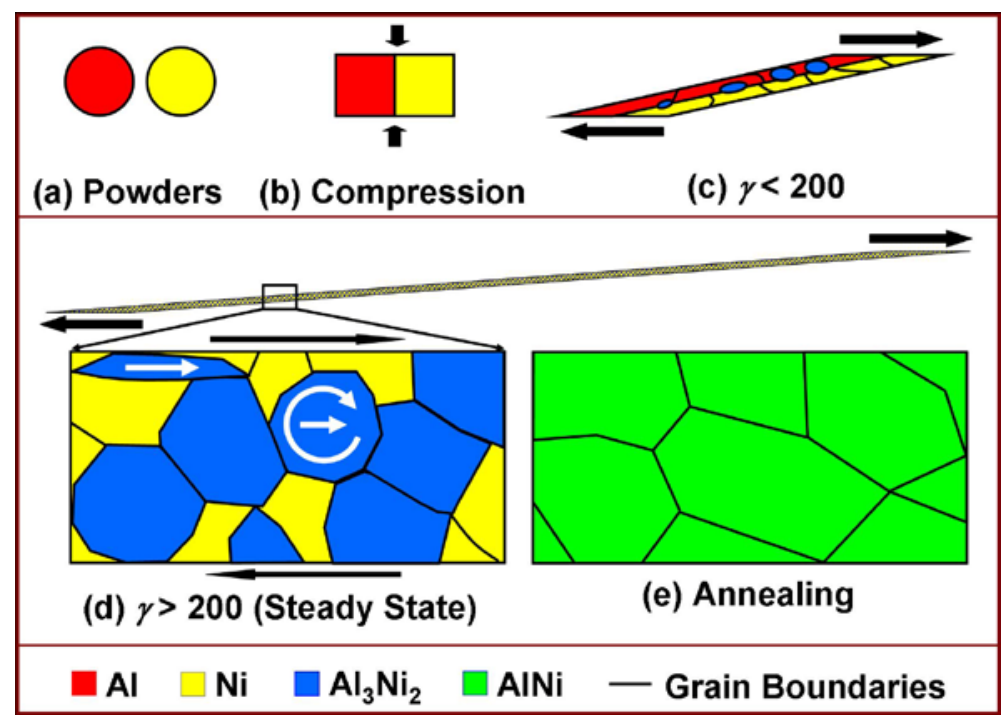

Figure 4. Schematic illustration of microstructural evolution and intermetallic formation with shear straining and annealing.

The grain sizes obtained in this study are at the nanometer level, i.e. much smaller than those of the HPT-processed pure metals. The formation of nanograins can be attributed to two main reasons: (i) the presence of a second phase blocks the motion of dislocations and the movement of grain boundaries; and (ii) the in situ formed intermetallics have strong covalent bonding. For the latter, it was reported that the grain size in materials with covalent bonding is reduced to the nanometer level by HPT [10,11,18,26].

The exact mechanism for the occurrence of the steady state at large strains is still under debate and it has been suggested that the steady state is reached by a balance between the hardening due to lattice defect generation and the softening due to lattice defect annihilation through dynamic recovery [27,28], dynamic recrystallization [29,30] and grain boundary migration [31,32]. The presence of the steady state in this study cannot be explained by dynamic recovery because shearing of grain boundaries increases the total fractions of grain boundaries, which leads to a continuous increase in hardness as discussed by Pippan [32]. Dynamic recrystallization and grain boundary migration [14-17] also cannot be the dominant mechanisms in this study because the presence of a second phase limits recrystallization and grain boundary migration. Although the intermetallic grains which are surrounded by the Ni grains may be fragmented, as reported in earlier papers concerning metal matrix composites [33,34], most of the nanograined intermetallics should not be deformed by shear straining at the steady state but rather slide and rotate with respect to each other 
(Fig. 4d) because of their dense fraction (84 vol.\%), small size and high hardness. This is consistent with the TEM observation (Fig. 2b) where no change in the grain shape occurs at the steady state.

The strain rate during HPT is high $\left(0.65 \mathrm{~s}^{-1}\right.$ at $5 \mathrm{~mm}$ from disc center) and grain boundary sliding is possible because of fast diffusion. For instance, a grain with a steady-state size of $28 \mathrm{n}$ $\mathrm{mm}$ located at a radius of $5 \mathrm{~mm}$ from the disc center is moved or elongated for $1100 \mathrm{~nm}$ in the shear direction with respect to neighboring grains by one revolution of HPT. Therefore, the atoms should move $1100 \mathrm{~nm}$ in $1 \mathrm{~min}$ ( $\omega=1 \mathrm{rpm}$ ) at a speed of $1.8 \times 10^{-8} \mathrm{~m} \mathrm{~s}^{-1}$ to keep the grain shape equiaxed. If the diffusion distance, $D$, is evaluated through $x=(D t)^{1 / 2}$ (where $D$ is the diffusion coefficient and $t$ is the time), and $x$ and $t$ are taken as $1100 \mathrm{~nm}$ and $60 \mathrm{~s}$, respectively, this gives an estimate of $D=2 \times 10^{-14} \mathrm{~m}^{2} \mathrm{~s}^{-1}$. This value is very similar to $\mathrm{D}$ for surface diffusion of $\mathrm{Al}$ and $\mathrm{Ni}$ when the activation energy is less than one-half of the activation energy for lattice diffusion, which is consistent with the diffusivity in HPT-processed Ag at room temperature [35]. The grain boundary sliding may also be controlled by dislocation motion [36], as the dislocations should move faster than the deformation speed. If the dislocation speed is evaluated through $v=\dot{\gamma} / \rho b$ (where $\dot{\gamma}$ is the strain rate, $\rho$ is the density of mobile dislocations and $b$ is the Burgers vector), and $\dot{\gamma}, \rho$ and $b$ are taken as $0.65 \mathrm{~s}^{-1}, 10^{16} \mathrm{~m}^{-2}$ (maximum density estimated from XRD results) and $0.25 \mathrm{~nm}$, respectively, a minimum $v=2.6 \times 10^{-7} \mathrm{~m} \mathrm{~s}^{-1}$ is achieved, which is much higher than $v=1.8 \times 10^{-8} \mathrm{~m} \mathrm{~s}^{-1}$ calculated from the deformation speed in this study.

In summary, bulk ultrahigh-strength $\mathrm{Al}_{3} \mathrm{Ni}_{2} / \mathrm{Ni}$ nanocomposites are produced from $\mathrm{Al}$ and $\mathrm{Ni}$ micropowder mixtures by solid-state reactions under intense shear straining. Such nanocomposites are completely transformed to nanostructured AlNi intermetallics after subsequent annealing at a temperature as low as $30 \%$ of the melting temperature of AlNi. The production of intermetallics using this process, which is not limited to the Al-Ni system, is based on the accelerated diffusion and short diffusion paths achieved by imposing intense shear strains.

One of the authors (K.E.) thanks the Japan Society for Promotion of Science (JSPS) for a postdoctoral scholarship. This work was supported in part by a Grant-in-Aid for Scientific Research from the MEXT, Japan, in Innovative Areas "Bulk Nanostructured Metals” and in part by Kyushu University Interdisciplinary Programs in Education and Projects in Research Development (P\&P).

[1] J.H. Westbrook, R.L. FleischerIntermetallic Compounds, Principles and Practice, vol. 1, John Wiley \& Sons, Chichester, 1995.

[2] D.L. Anton, P.L. Martin, D.B. Miracle, R. McMeeking, Symposium Proceeding on Intermetallic Matrix Composites, vol. 194, Materials Research Society, 1990.

[3] J.A. Haber, J.L. Crane, W.E. Buhro, C.A. Frey, S.M.L. Sastry, J.J. Balbach, M.S. Conradi, Adv. Mater. 8 (1996) 163-166.

[4] S. Suryanarayana, Prog. Mater. Sci. 46 (2001) 1-184.

[5] H. Gleiter, Prog. Mater. Sci. 33 (1989) 223-315.

[6] Y.B. Pithawalla, M.S. El-Shall, S.C. Deevi, Intermetallics 8 (2000) 1225-1231.

[7] S.O. Moussa, M.S. El-Shall, Mater. Chem. Phys. 112 (2008) 1015-1020. 
[8] R.Z. Valiev, Y. Estrin, Z. Horita, T.G. Langdon, M.J. Zehetbauer, Y.T. Zhu, JOM 58 (4) (2006) 33-39.

[9] R.Z. Valiev, T.G. Langdon, Metall. Mater. Trans. A 528 (2011) 6140-6148.

[10] S.X. McFadden, R.S. Mishra, R.Z. Valiev, A.P. Zhilyaev, A.K. Mukherjee, Nature 398 (1999) 684-686.

[11] J.Y. Huang, Y.T. Zhu, X.Z. Liao, R.Z. Valiev, Phil. Mag. Lett. 84 (2004) 183-190.

[12] E. Menendez, G. Salazar-Alvarez, A.P. Zhilyaev, S. Surinach, M.D. Baro, J. Nogues, J. Sort, Adv. Funct. Mater. 18 (2008) 3293-3298.

[13] K. Edalati, H. Iwaoka, Z. Horita, M. Tanaka, K. Higashida, H. Fujiwara, K. Ameyama, Kovove Mater. 49 (2011) 85-92.

[14] A.P. Zhilyaev, T.G. Langdon, Prog. Mater. Sci. 53 (2008) 893-979.

[15] K. Edalati, Z. Horita, Scripta Mater. 63 (2010) 174-177.

[16] M.T. Perez-Prado, A.A. Gimazov, O.A. Ruano, M.E. Kassner, A.P. Zhilyaev, Scripta Mater. 58 (2008) 219-222.

[17] K. Edalati, Z. Horita, H. Fujiwara, K. Ameyama, Metall. Mater. Trans. A 41 (2010) 3308-3317.

[18] K. Edalati, S. Toh, Y. Ikoma, Z. Horita, Scripta Mater. 65 (2011) 974-977.

[19] M. Kawasaki, B. Ahn, T.G. Langdon, J. Mater. Sci. 45 (2010) 4583-4593.

[20] M. Kawasaki, R.B. Figueiredo, T.G. Langdon, Acta Mater. 59 (2011) 308-316.

[21] A.P. Zhilyaev, S. Lee, G.V. Nurislamova, R.Z. Valiev, T.G. Langdon, Scripta Mater. 44 (2001) 2753-2758.

[22] T. Fujita, Z. Horita, T.G. Langdon, Mater. Sci. Eng. A 241 (2004) 241-250.

[23] S.V. Divinski, J. Ribbe, D. Baither, G. Schmitz, G. Reglitz, H. Rosner, K. Sato, Y. Estrin, G. Wilde, Acta Mater. 57 (2009) 5706-5717.

[24] B. Oberdorfer, B. Lorenzoni, K. Unger, W. Sprengel, M.J. Zehetbauer, R. Pippan, R. Wurschum, Scripta Mater. 63 (2010) 452-455.

[25] M. Watanabe, Z. Horita, M. Nemoto, Interface Sci. 4 (1997) 229-241.

[26] K. Edalati, Z. Horita, Acta Mater. 59 (2011) 6831-6836.

[27] M.J. Zehetbauer, Acta. Metall. Mater. 41 (1993) 589-599.

[28] F.A. Mohamed, Acta Mater. 51 (2003) 4107-4119.

[29] N. Hansen, Metall. Mater. Trans. A. 32 (2001) 2917-2935.

[30] T. Hebesberger, H.P. Stuwe, A. Vorhauer, F. Wetscher, R. Pippan, Acta Mater. 53 (2005) 393-402.

[31] A. Mishra, B.K. Kad, F. Gregori, M.A. Meyers, Acta Mater. 55 (2007) 13-28.

[32] R. Pippan, S. Scheriau, A. Taylor, M. Hafok, A. Hohenwarter, A. Bachmaier, Annu. Rev. Mater. Res. 40 (2010) 319-343.

[33] I. Sabirov, O. Kolednik, R. Pippan, Metall. Mater. Trans. A 36 (2005) 2861-2870.

[34] K. Edalati, H. Iwaoka, Z. Horita, M. Konno, T. Sato, Mater. Sci. Eng. A 529 (2011) 435-441.

[35] H. Matsunaga, Z. Horita, Mater. Trans. 50 (2009) 1633-1637.

[36] T.G. Langdon, Acta Metall. Mater. 42 (1994) 2437-2443. 